\title{
Predictions of opposite-sex attitudes concerning gender-related social issues
}

\author{
ED M. EDMONDS, DELWIN D. CAHOON, and MARGARET SHIPMAN \\ Augusta College, Augusta, Georgia
}

\begin{abstract}
Men and women college students indicated the extent of their agreement with statements concerning sex-role stereotyping, adversarial sexual beliefs, sexual conservatism, acceptance of interpersonal violence, and rape-myth acceptance, and they also predicted the opinion of a typical member of the opposite sex. In all comparisons, the opinions of the men and the women were not significantly different. Although the men were very accurate in predicting the women's opinions, the women consistently predicted that the men were more negatively biased than the actual opinions expressed by the men would indicate.
\end{abstract}

Several studies have suggested that men and women differ in their perceptions of sexual intent. Abbey (1982) reported that men tend to misinterpret the friendly behavior of women as indicating sexual intent. Shotland and Craig (1988) found that males perceive role players of both sexes to be more sexually interested in their roleplaying partners than females do. These results are generally attributed to a form of sex-role socialization that influences men to interpret ambiguous stimuli as indicating sexual interest.

Other evidence, however, suggests that men and women have similar perceptions about sexual interest and love. Shotland and Craig (1988) found that both men and women can differentiate between friendly and sexually interested behavior even when the stimuli are ambiguous. Hendrick and Hendrick (1986) found no difference in opinion between men and women regarding passionate love and selfless love. Edmonds and Cahoon (1984) reported a point-biserial correlation of .85 between ratings of women and men concerning the sexual arousal value to men of various items of women's clothing. In addition, men and women were found to be in almost perfect agreement concerning the items of clothing judged to have the greatest arousal value for men. Burt (1980) also found very strong similarities between men and women with regard to attitudinal variables and rape-myth acceptance.

Although men and women do have similar views about certain aspects of sexuality, it would be of interest to determine how accurately each sex can predict the attitudes of the opposite sex. This question was investigated in a study by Cahoon and Edmonds (1989), in which both male and female students were asked to rate female models on certain aspects of sexuality and then to predict the response of a typical member of the opposite sex. Differences were

Reprint requests may be sent to Ed Edmonds, Psychology Department, Augusta College, Augusta, GA 30910. found between men and women with respect to accuracy in predicting the opinions of the opposite sex, with women making significantly more errors.

The present study was designed to compare the typical responses of males and females, as well as the accuracy with which males and females can estimate the opinions of the opposite sex, with respect to sex-role stereotyping, adversarial sexual beliefs, sexual conservatism, acceptance of interpersonal violence, and rape-myth acceptance.

\section{METHOD}

Subjects

The subjects were 47 male and 60 females enrolled in introductory psychology classes at Augusta College. No special incentives to participate in the experiment were offered.

\section{Procedure}

Each student responded to items constituting the scales used by Burt (1980) to measure attitudes toward sex-role stereotyping, adversarial sexual beliefs, sexual conservatism, acceptance of interpersonal violence, and rape-myth acceptance. Responses to all items were worded on a 7-point scale ranging from "strongly agree" to "strongly disagree." After recording an opinion concerning each statement, each student predicted the opinion of a typical member of the opposite sex.

\section{RESULTS AND DISCUSSION}

For each of the five scales, the data were analyzed with a repeated measures analysis of variance; the factors were sex of rater and own versus estimated opposite-sex opinion.

No significant differences existed between the opinions of the men and women students. However, although the men predicted the women's opinions quite accurately, the women predicted that the men would endorse stereotypic $[F(1,104)=28.64, p<.001]$, adversarial $[F(1,105)=$ $85.83, p<.001]$, interpersonal-violence $[F(1,105)=$ $77.20, p<.001]$, rape-myth $[F(1,105)=8.97$, $p<.003$ ] attitudes to a significantly greater extent than 
the men actually endorsed these attitudes. The results are consistent with the findings of Cahoon and Edmonds (1989) that women misjudge men's sexual attitudes, especially men's motivation to rape.

Cahoon and Edmonds (1989) have suggested that, corresponding to the tendency of men to see more sexual intent in females than females do (Abbey, 1982; Abbey, Cozzarelli, McLaughlin, \& Harnish, 1987), there appears to be a tendency for females to see more negative sexual bias in males than males actually report. Apparently women believe that they are viewed by men much more negatively than men evaluate them.

It should be noted that attitudes and behaviors are not always consistent. For example, Muehlenhard and Hollabaugh (1988) indicated that $39 \%$ of the women in their study engaged in token resistance to sex-saying "no" but meaning "yes." A possible cause for this behavior may be related to the sexual double standard, according to which sexually active women are evaluated negatively (Muehlenhard \& McCoy, 1989). Shotland and Craig (1988) found that although men and women can differentiate equally well between friendly behavior and behavior with sexual intent, men report more sexual intent in behavior than women do. An explanation for this result may also be related to the sexual double standard, in that women may report less sexual intent than they perceive because it is more socially appropriate for women not to openly acknowledge their interest in sex (Muehlenhard \& McCoy, 1989). Likewise, either the attributions made by the females in the present study may reflect actual male attitudes more accurately than the stated attitudes of the males or the attributions may indicate a double standard bias to view males as less sexually "pure" than females.

Shotland and Craig (1988) have pointed out that "neither the sender nor the receiver is objective, and there is no objective criterion by which to judge bias.... All that can and should be said is that men and women have different thresholds for labeling interested behavior" (p. 71). However, acceptance of the sexual double standard can hamper honest communication, and, in some circumstances, it may even increase the incidence of crimes against women (Edmonds \& Cahoon, 1986). Research is planned to determine the causes of the perceptual gender differences found in this study as well as the extent to which these differences in attributions affect actual interactions between men and women.

\section{REFERENCES}

AbBey, A. (1982). Sex differences in attribution for friendly behavior; Do males misperceive females' friendliness? Journal of Personality \& Social Psychology, 42, 830-838.

Abbey, A., Cozzareli, C., Mclaughuin, K., \& Harnish, R. J. (1987). The effects of clothing and dyad sex composition on perceptions of sexual intent: Do women and men evaluate these cues differently? Journal of Applied Social Psychology, 17, 108-126.

BURT, M. R. (1980). Cultural myths and supports for rape. Journal of Personality \& Social Psychology, 38, 217-230.

CAHOON, D. D., \& Edmonds, E. M. (1989). Male-female estimates of opposite-sex first impressions concerning females' clothing styles. Bulletin of the Psychonomic Society, 27, 280-281.

Edmonds, E. M., \& CAHOON, D. D. (1984). Female clothes preference related to male sexual interest. Bulletin of the Psychonomic Society, 22, 171-173.

EDmonds, E. M., CAHOON, D. D. (1986). Attitudes concerning crimes related to clothing worn by female victims. Bulletin of the Psychonomic Society, 24, 444-446.

Hendrick, C., \& HeNDrick, S. (1986). A theory and method of love. Journal of Personality \& Social Psychology, 50, 392-402.

Muehlenhard, C. L., \& Hollabaugh, L. C. (1988). Do women sometimes say no when they mean yes? The prevalence and correlates of women's token resistance to sex. Journal of Personality \& Social Psychology, 54, 872-879.

Muehlenhard, C. L.; McCoy, M. L. (1989, August). The sexual double standard and women's token resistance to sex. Paper presented at the annual meeting of the American Psychological Association, New Orleans.

Shotland, R. L., \& Craig, J. M. (1988). Can men and women differentiate between friendly and sexually interested behavior? Social Psychology Quarterly, 51, 66-73.

(Manuscript received December 10, 1990.) 